\title{
STRUKTUR DAN KOMPOSISI HUTAN DI KAWASAN LINDUNG RANTAU BERTUAH, KABUPATEN SIAK, PROVINSI RIAU
}

\section{Structure and composition of the forests in Rantau Bertuah protected area, Siak Regency, Riau Province}

\author{
Nur Muhammad Heriyanto ${ }^{1, *}$, Dolly Priatna ${ }^{2,5}$, Kuswata Kartawinata ${ }^{3}$, Ismayadi Samsoedin ${ }^{4}$ \\ ${ }^{1}$ Pusat Penelitian dan Pengembangan Hutan, Badan Litbang Kehutanan dan Inovasi, \\ Kementerian Lingkungan Hidup dan Kehutanan; \\ 2 Program Pascasarjana, Universitas Pakuan Bogor; \\ ${ }^{3}$ Integrative Research Center, The Field Museum of Natural History, \\ 1400 Lake Shore Drive, Chicago, IL 60605, USA; \\ ${ }^{4}$ Yayasan Sahabat Pohon Indonesia; \\ ${ }^{5}$ Divisi Sustainability \& Stakeholder Engagement, Asia Pulp and Paper Group \\ *Email: nurmheriyanto88@yahoo.com
}

Diterima/Received: 12 Januari 2020; Disetujui/Accepted: 29 Maret 2020

\begin{abstract}
A study on structure and composition of old secondary forest (OSF), young secondary forest (YSF), and old scrub forest (OScF) in Rantau Bertuah Protected Area, Siak Regency, Riau Province, was conducted in September 2018. The purpose of this study was to analyze species composition and structure of forests. The research plot measuring $100 \times 100 \mathrm{~m}$ (one ha) each was made at OSF, YSF, and OSCF. The OSF plot held 33 families, 55 species, and 642 trees with a diameter of $\geq 10 \mathrm{~cm}$; in YSF 31 families, 56 species, and 450 trees; and in OScF 28 families, 52 species, and 235 trees. At the tree level the OSF was dominated by Calophyllum macrocarpum, Shorea sp., and Gironniera nervosa; the YSF by Palaquium amboinense, Shorea macroptera, and Gironniera nervosa; and the OScF by Macaranga hypoleuca, Gironniera nervosa and Lithocarpus gracilis. Based on the main dominant species and full distribution in the plot, the forest is called the Gironniera nervosaLithocarpus gracilis association.
\end{abstract}

Keywords: composition, protected forest, regeneration, structure

\begin{abstract}
Abstrak
Penelitian struktur dan komposisi hutan sekunder tua (HST), hutan sekunder muda (HSM), dan hutan belukar tua (HBT) di Kawasan Lindung Rantau Bertuah, Kabupaten Siak, Provinsi Riau dilaksanakan pada bulan September 2018. Penelitian ini bertujuan untuk menganalisis komposisi jenis dan struktur tegakan hutan. Plot penelitian berukuran $100 \times 100 \mathrm{~m}$ (satu ha) dibuat di HSM, HST dan HBT. Hasil analisis menunjukkan bahwa di plot HST tercatat 33 suku, 55 jenis, dan 642 pohon berdiameter $\geq 10 \mathrm{~cm}$; di HSM tercatat 31 suku, 56 jenis, dan 450 pohon; dan di HBT 28 suku, 52 jenis, dan 235 pohon. Pada tingkat pohon di HST, hutan didominasi oleh Calophyllum macrocarpum, Shorea sp., dan Gironniera nervosa; di HSM oleh Palaquium amboinense, Shorea macroptera, dan Gironniera nervosa; dan di HBT oleh Macaranga hypoleuca, Gironniera nervosa, dan Lithocarpus gracilis. Berdasarkan jenis dominan utama dan sebaran penuh dalam plot, tipe komunitas ini dinamakan asosiasi Gironniera nervosa-Lithocarpus gracilis.
\end{abstract}

Kata kunci: hutan lindung, komposisi, regenerasi, struktur 


\section{PENDAHULUAN}

Hutan hujan tropik daerah rendah atau hutan pamah tropik di Sumatra mempunyai keanekaragaman jenis tumbuhan yang tinggi dan Dipterocarpaceae merupakan suku paling penting (Whitmore \& Tantra 1986). Hutan pamah Dipterocarpaceae merupakan pusat keanekaragaman jenis dan pusat sebaran suku dan marga tumbuhan di kawasan Malesia (Whitmore 1986, Kartawinata 2013). Selama empat dasa-warsa terakhir, hutan Sumatra telah banyak dibalak dan dikonversi menjadi perkebunan kelapa sawit dan hutan tanaman industri. Hutan yang masih utuh sebagian besar hanya terdapat di perbukitan dan pegunungan.

Informasi tentang vegetasi dan fisiografi Sumatra telah disarikan oleh Laumonier (1997) dan uraian singkat tentang hutan Sumatra dikemukakan oleh Whitten et al. (1984). Penelitian tentang komposisi jenis dan penebangan hutan di Sumatra cukup banyak dan tersebar di berbagai lokasi, antara lain Kartawinata et al. (2004), Priatna et al. (2006), Onrizal et al. (2008), Samsoedin et al. (2009, 2014), Laumonier et al. (2010), Dharmawan \& Samsoedin (2012), Rosalina et al. (2013, 2014), Wardani \& Heriyanto (2015), Rahmah et al. (2016), dan Heriyanto et al. (2019). Di Riau tercatat beberapa penelitian yang dilakukan antara lain: oleh Gillison et al. (2001), Polosakan et al, (2001), dan Rosalina et al. (2014). Penelitian tentang biomassa dan stok karbon di hutan Riau, antara lain Whitten et al. (1984), Rosalina et al. (2013), Yuniawati (2013), dan Widhi \& Murti (2013).

Hutan pamah di Riau telah banyak dirusak oleh pembalakan dan konversi menjadi hutan tanaman industri, perkebunan kelapa sawit, perladangan dan pemanfaatan lain. Hutan-hutan alami yang telah terganggu dan hutan sekunder berbagai umur banyak terdapat di Riau. Hutan sekunder dan belukar tua telah dipilih sebagai objek penelitian dan ditelaah dari segi komposisi jenis dan struktur tegakannya.

Tujuan penelitian ini adalah untuk mengetahui komposisi jenis dan struktur tegakan hutan. Data dan informasi yang diperoleh dari penelitian ini akan bermanfaat untuk berbagai keperluan termasuk konservasi, pengelolaan, dan restorasi.

\section{BAHAN DAN METODE}

\section{Lokasi dan waktu}

Penelitian dilaksanakan pada bulan September 2018 di kelompok hutan lindung Rantau Bertuah, Kabupaten Siak, Provinsi Riau. Secara administrasi, lokasi ini termasuk Desa Rantau Bertuah, Kecamatan Minas, Kabupaten Siak, Provinsi Riau.

Lokasi penelitian terletak pada ketinggian \pm $60 \mathrm{~m}$ dpl. (meter di atas permukaan laut) dan merupakan bagian hutan hujan tropik pamah. Topografinya landai dengan kelerengan 0-8\%. Tanah di lokasi penelitian sebagian besar termasuk Podzolik Merah Kuning, dengan pH 4-6, dan tingkat kesuburan rendah (Pusat Penelitian Tanah dan Agroklimat 1993, Soil Survey Staff 2003). Bahan induk terdiri dari batuan endapan, batu pasir (sandstone) dan deposit pasir (sand deposit). Solum tanah tebal, berwarna merah sampai kuning dengan variabel tekstur konsisten, asam, kandungan nutrisi rendah, permeabilitas rendah sampai medium dan sangat mudah tererosi (Anonim 2017).

Menurut klasifikasi Schmidt \& Ferguson (1951), iklim di lokasi penelitian termasuk ke dalam tipe iklim A. Curah hujan tahunan $2.598,7 \mathrm{~mm}$, curah hujan minimum sebesar $66,7 \mathrm{~mm} /$ bulan pada bulan Januari dengan 12 hari hujan. Curah hujan maksimum sebesar 439,5 mm/bulan terjadi pada bulan November dengan 27 hari hujan. Suhu rata-rata di areal ini terendah $\left(26^{\circ} \mathrm{C}\right)$ terjadi pada bulan September dan tertinggi $\left(28,1^{\circ} \mathrm{C}\right)$ pada bulan Juni, kelembapan udara berkisar antara $69 \%$ dan $83 \%$ (BPS 2017).

\section{Bahan dan alat}

Bahan penelitian yang dipilih dan diidentifikasi dengan menggunakan citra satelit dua tahun terakhir (HCS Approach Toolkit 2017) adalah tegakan hutan sekunder tua (HST, koordinat $101^{\circ} 20^{\prime} 58,8^{\prime \prime}$ BT dan $0^{\circ} 43^{\prime}$ 50,5” LU), hutan sekunder muda (HSM, koordinat $101^{\circ} 21^{\prime}$ 45,0" BT dan $\left.0^{\circ} 43^{\prime} 59,5^{\prime \prime} \mathrm{LU}\right)$ dan hutan belukar tua (HBT, koordinat $101^{\circ} 19^{\prime} 18,2^{\prime \prime}$ BT dan $0^{\circ} 43^{\prime}$ $50,0^{\prime \prime}$ LU). Lokasi penelitian termasuk ke dalam kawasan lindung Rantau Bertuah yang merupakan bagian dari kawasan hutan lindung seluas \pm 6.557 ha di Kabupaten Siak, Provinsi Riau. Alat yang digunakan dalam penelitian ini adalah: GPS (global 
positioning system), meteran, pita diameter (diameter tape), tali plastik, alat ukur tinggi pohon, pisau/gunting stek, kantong plastik, alkohol, kertas koran, etiket gantung untuk contoh herbarium, dan alat-alat tulis.

\section{Rancangan penelitian dan pengambilan contoh}

Penelitian dilakukan dengan menggunakan metode kuadrat (Mueller-Dombois \& Ellenberg 2016). Plot penelitian yang berbentuk bujur sangkar seluas satu hektar dengan ukuran $100 \mathrm{x}$ $100 \mathrm{~m}$ diletakkan secara acak di setiap tegakan. Luasan satu ha dianggap dapat mewakili tegakan hutan sekunder (Riswan dan Kartawinata 1988, Rosalina et al. 2014, Heriyanto et al. 2018). Di dalam plot bujur sangkar tersebut dibuat sub-plot berukuran $20 \times 20 \mathrm{~m}$, dalam plot satu ha terdapat 25 subplot, dan di dalam subplot ini disarangkan subplot $5 \times 5 \mathrm{~m}$ serta subplot $2 \times 2 \mathrm{~m}$ (Gambar 1 ).

Pohon, pancang, dan semai dalam plot direkam, berdasarkan kriteria Kartawinata et al. (2004), Irwanto (2006), dan Wardani et al. (2017) sebagai berikut:

1. Pohon adalah tumbuhan berkayu dengan DSD (diameter setinggi dada sekitar $1,3 \mathrm{~m}$ ) $\geq 10 \mathrm{~cm}$; bila pohon berbanir diameter diukur $20 \mathrm{~cm}$ di atas banir.

2. Pancang adalah anakan pohon atau permudaan yang tingginya $>1,5 \mathrm{~m}$ dengan $\mathrm{DSD}<10 \mathrm{~cm}$.

3. Semai adalah anakan mulai dari kecambah sampai anakan dengan tinggi $\leq 1,5 \mathrm{~m}$.

Semua pohon dalam subplot $(20 \times 20 \mathrm{~m})$ dan pancang dalam subplot $(5 \times 5 \mathrm{~m})$ diukur diameter dan tingginya serta dicatat nama jenisnya. Semai dalam subplot $2 \times 2 \mathrm{~m}$ dihitung jumlahnya dan dicatat nama jenisnya. Contoh herbarium jenisjenis tersebut diambil dan diidentifikasi di Laboratorium Botani dan Ekologi Hutan, Pusat Penelitian dan Pengembangan Hutan, Bogor. Tata nama jenis mengikuti Whitmore \& Tantra (1986) dan The Plant List (2013).

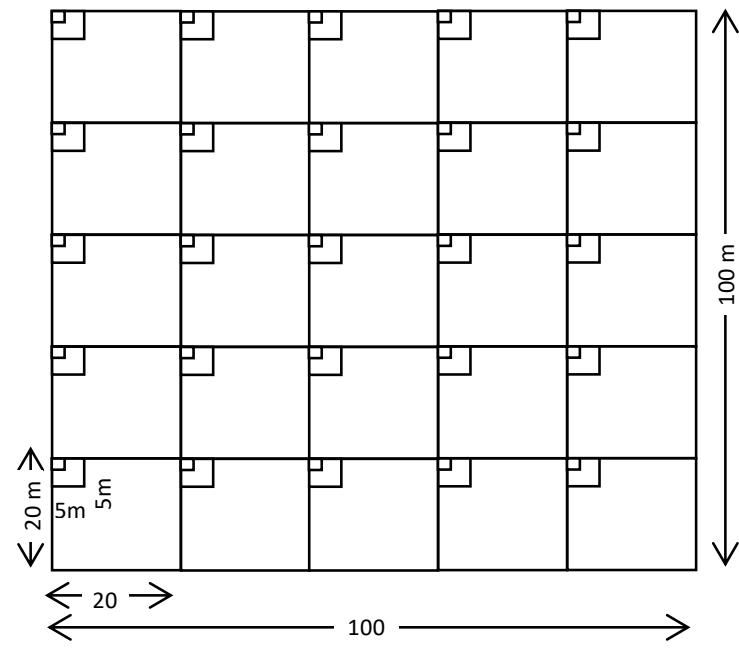

Gambar 1. Plot penelitian berukuran $100 \times 100$ m (1 ha) dibagi menjadi 25 subplot pohon berukuran $20 \times 20 \mathrm{~m}$. Subplot pancang $(5 \times 5 \mathrm{~m})$, dan subplot semai $(2 \times 2 \mathrm{~m})$ disisipkan menyarang dalam setiap subplot pohon

\section{Analisis data}

Data yang diperoleh dianalisis untuk menentukan:

1. Komposisi, struktur, dan nilai kepentingan masing-masing jenis dalam komunitas berdasarkan penutupan (coverage), yang dapat dinyatakan dengan AD atau area dasar (basal area); $\mathrm{K}$ atau kerapatan (density) dan $\mathrm{F}$ atau sebaran (frequency) (Cox 1992). Nilai Kepentingan (Importance Value) atau NK (Mueller-Dombois \& Ellenberg 2016) yaitu penjumlahan nilai relatif kerapatan (KR), frekuensi (FR), dan area dasar (ADR). Jenis dominan merupakan jenis yang mempunyai nilai kepentingan tertinggi di dalam suatu komunitas (Kusmana 2011, Mueller-Dombois \& Ellenberg 2016). Diagram profil tegakan hutan di lokasi penelitian (a) hutan sekunder tua (HST), (b) hutan sekunder muda (HSM), dan (c) hutan belukar tua (HBT) dibuat menurut metode Kartawinata et al. (2004). Kesamaan komposisi jenis dalam HST, HSM, dan HBT dihitung dengan rumus Indeks Kesamaan (IK) Jaccard (Mueller-Dombois \& Ellenberg 2016) sebagai berikut: $I K=\frac{c}{A+B-c} \times 100 \%$

di mana $A$ adalah jumlah total semua jenis dalam plot $A, B$ jumlah total jenis dalam plot $B$, dan $C$ adalah jumlah jenis bersama yang terdapat di plot A dan plot B.

2. Parameter vegetasi lain adalah: (a) Potensi jenis dalam plot penelitian yang dikategorikan ke 
dalam tiga tingkat pertumbuhan yaitu semai, pancang, dan pohon yang masing-masing dihitung dalam satuan luas (ha). (b) Potensi tegakan meliputi volume tegakan dan jumlah batang per ha yang diklasifikasikan menurut kelas diameter: 10-19 cm, 20-29 cm, $30-39$ $\mathrm{cm}, 40-49 \mathrm{~cm}$, dan $\geq 50 \mathrm{~cm}$.

\section{HASIL DAN PEMBAHASAN}

\section{Komposisi vegetasi}

Hasil identifikasi jenis tumbuhan di hutan sekunder tua, hutan sekunder muda, dan belukar tua di lokasi penelitian disajikan dalam Tabel 1. Dalam tiga plot penelitian tercatat 73 jenis pohon dengan total jumlah pohon di tiga plot sebanyak 1.327 pohon dan kerapatan rata-rata 442 pohon/ha. Ringkasan data untuk masing-masing tipe hutan tercantum dalam Tabel 2.

Dari segi komposisi jenis pohon ketiga tegakan hutan dalam plot penelitian merupakan satu tipe komunitas atau unit vegetasi, yang dapat disebut asosiasi (Kartawinata 1994, Sheil et al. 2010). Berdasarkan dua jenis tumbuhan dominan utama dan sebaran penuh dalam plot tipe komunitas ini dinamakan asosiasi Gironniera nervosa-Lithocarpus gracilis atau disingkat asosiasi Gironniera-Lithocarpus. Jenis-jenis yang mencirikan asosiasi ini adalah jenis-jenis yang tergabung dalam Kelompok 1 dalam Tabel 1, yaitu jenis-jenis yang terdapat di semua plot dengan nilai kepentingan (NK) dan kerapatan (K) yang bervariasi. Dalam setiap plot terdapat jenis-jenis dominan (NK > 10\%) yang khas, seperti tercantum dalam Tabel 3. Suku yang dominan di hutan sekunder tua dan belukar tua adalah Dipterocarpaceae, Euphorbiaceae, dan Leguminosae; sedangkan di hutan sekunder muda adalah Dipterocarpaceae, Euphorbiaceae, dan Leguminosae. Sebaran, NK, dan K jenis-jenis tercantum dalam Kelompok 2-6 adalah sebagai berikut:

1. Kelompok 2: jenis-jenis yang terdapat di hutan sekunder tua dan sekunder muda.

2. Kelompok 3: jenis-jenis yang khas hanya terdapat di hutan sekunder muda.
3. Kelompok 4: jenis-jenis yang terdapat di hutan sekunder muda dan belukar tua.

4. Kelompok 5: jenis-jenis yang khas hanya terdapat di belukar tua.

5. Kelompok 6: jenis-jenis yang terdapat di hutan sekunder tua dan belukar tua.

Perbandingan komposisi jenis di hutan sekunder tua (HST), hutan sekunder muda (HSM), dan belukar tua (HBT) diperoleh indeks kesamaan :

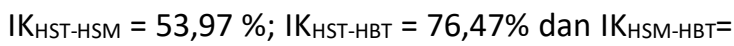
42,25\%. Dalam hutan sekunder dan belukar ini masih terdapat 14 jenis Dipterocarpaceae (Tabel 1) dengan diameter $10-50 \mathrm{~cm}$. Jenis yang paling menonjol adalah Hopea sangal dengan kerapatan rata-rata 14 pohon/ha, Parashorea smythiesii dengan kerapatan rata-rata 20 pohon/ha, dan Shorea macroptera dengan kerapatan rata-rata 30 pohon/ha. Sementara itu sebatang Hopea polycarpa terdapat di belukar tua dengan diameter $>50 \mathrm{~cm}$. Kehadiran jenis-jenis Dipterocarpaceae yang sedikit dengan pola sebaran kelas diameter yang tidak beraturan disebabkan oleh penebangan selektif pada masa lalu. Menggunakan acuan yang tersedia (Whitmore 1986, Riswan \& Kartawinata 1988, Corlett 1991, Kartawinata 1994, Keßler et al. 2000, Priatna et al. 2006) di tiga hutan penelitian dapat diidentifikasi 18 jenis sekunder $(25,4 \%)$, jadi dari keseluruhan $74,6 \%$ adalah jenis-jenis hutan primer. Yang paling menonjol di hutan sekunder tua adalah jenis Gironniera nervosa dengan $\mathrm{K}$ (Kerapatan) 50 pohon/ha; Dialium indum $(\mathrm{K}=21$ pohon/ha); Macaranga hypoleuca ( $\mathrm{K}=18$ pohon/ha), dan Endospermum diadenum ( $\mathrm{K}=16$ pohon/ha); di hutan sekunder muda adalah Gironniera nervosa ( $\mathrm{K}=41$; Acacia mangium ( $\mathrm{K}=36$ pohon/ha) dan Endospermum diadenum ( $\mathrm{K}=11$ pohon/ha; dan di belukar tua adalah Macaranga hypoleuca ( $\mathrm{K}=35$ pohon/ha; Gironniera nervosa (K = 23), dan Gonocaryum gracile ( $\mathrm{K}=13$ pohon/ha). Shorea leprosula sering terdapat bersama-sama jenis pionir dan sekunder sehingga tidak mengherankan hadir dalam petak-petak penelitian hutan sekunder ini (Tabel 1). Dari aspek kerapatan (K) dan nilai kepentingan (NK) Gironniera nervosa dominan di tiga plot penelitian disajikan dalam (Tabel 1). 
Tabel 1. Kerapatan (K) dan nilai kepentingan (NK) jenis-jenis pohon (DSD $\geq 10 \mathrm{~cm}$ ) di hutan sekunder tua, hutan sekunder muda, dan belukar tua di kawasan hutan lindung Rantau Bertuah, Riau

\begin{tabular}{|c|c|c|c|c|c|c|c|}
\hline \multirow[t]{2}{*}{ No } & \multirow[t]{2}{*}{ Jenis } & \multicolumn{2}{|c|}{$\begin{array}{l}\text { Hutan } \\
\text { sekunder }\end{array}$} & \multicolumn{2}{|c|}{$\begin{array}{c}\text { Hutan } \\
\text { sekunder } \\
\text { muda }\end{array}$} & \multicolumn{2}{|c|}{ Belukar tua } \\
\hline & & $\mathbf{K}$ & NK & $\mathbf{K}$ & NK & K & NK \\
\hline & KELOMPOK 1 & & & & & & \\
\hline 1 & Calophyllum macrocarpum Hook.f. & 74 & 27,88 & 23 & 13,48 & 6 & 7,27 \\
\hline 2 & Gironniera nervosa Planch. & 50 & 19,99 & 41 & 24,80 & 23 & 22,48 \\
\hline 3 & Lithocarpus gracilis (Korth.) Soepadmo & 35 & 17,53 & 16 & 10,77 & 13 & 22,12 \\
\hline 4 & Palaquium amboinense Burck & 39 & 16,73 & 42 & 25,43 & 5 & 5,71 \\
\hline 5 & Shorea macroptera Dyer & 41 & 16,70 & 44 & 23,98 & 7 & 11,52 \\
\hline 6 & Nephelium lappaceum L. & 26 & 11,51 & 5 & 3,87 & 3 & 3,60 \\
\hline 7 & Endospermum diadenum (Miq.) Airy Shaw. & 16 & 10,01 & 11 & 7,48 & 5 & 8,57 \\
\hline 8 & Dialium indum L. & 21 & 9,07 & 3 & 2,18 & 1 & 1,70 \\
\hline 9 & Parashorea smythiesii Wyatt-Sm. ex P.S. Ashton & 19 & 8,26 & 32 & 17,73 & 5 & 5,25 \\
\hline 10 & Hopea sangal Korth & 17 & 7,76 & 22 & 14,35 & 3 & 4,76 \\
\hline 11 & Hopea pachycarpa (Heim.) Sym. & 12 & 5,97 & 1 & 0,71 & 2 & 7,61 \\
\hline 12 & Knema cinerea (Poir.) Warb. & 13 & 6,36 & 6 & 4,20 & 8 & 8,88 \\
\hline 13 & Diospyros ulo Merr. & 11 & 5,23 & 3 & 2,16 & 4 & 5,49 \\
\hline 14 & Magnolia bintuluensis (Agostini) Noot. & 6 & 3,44 & 4 & 3,05 & 2 & 4,22 \\
\hline 15 & Acacia mangium Willd. & 5 & 3,12 & 36 & 30,07 & 1 & 1,27 \\
\hline 16 & Artocarpus elasticus Reinw. ex Blume & 2 & 1,92 & 3 & 2,46 & 1 & 3,69 \\
\hline 17 & Macaranga tilloba (Thunb.) Muell. Arg & 4 & 1,85 & 11 & 6,73 & 8 & 7,99 \\
\hline 18 & Gluta renghas $\mathrm{L}$. & 4 & 2,14 & 1 & 0,71 & 1 & 2,28 \\
\hline 19 & Neoscortechinia kingii (Hook.f.) Pax \& K. Hoffm. & 4 & 2,04 & 1 & 0,81 & 8 & 9,93 \\
\hline 20 & Artocarpus kemando Miq. & 3 & 1,64 & 3 & 2,35 & 7 & 10,29 \\
\hline 21 & Aporosa frutescens Blume & 3 & 1,62 & 6 & 4,91 & 1 & 1,31 \\
\hline 22 & Koompassia sp. & 2 & 0,81 & 3 & 3,08 & 6 & 8,16 \\
\hline 23 & Shorea leprosula Miq. & 2 & 1,06 & 9 & 6,76 & 5 & 6,31 \\
\hline 24 & Ilex cymosa Blume & 2 & 1,05 & 7 & 4,40 & 2 & 2,75 \\
\hline 25 & Gonocaryum gracile Miq. & 1 & 0,52 & 4 & 3,40 & 13 & 13,66 \\
\hline 26 & $\begin{array}{l}\text { Dillenia excelsa Gilg. } \\
\text { KELOMPOK } 2\end{array}$ & 1 & 0,49 & 3 & 2,17 & 1 & 1,34 \\
\hline 1 & Anisophyllea disticha Baill. & 3 & 1,22 & 13 & 7,33 & - & - \\
\hline 2 & Averrhoa sp. & 3 & 1,72 & 1 & 0,70 & - & - \\
\hline 3 & Dysoxylum excelsum Blume & 33 & 13,69 & 9 & 6,09 & - & - \\
\hline 4 & Garcinia rigida Miq. & 1 & 0,51 & 12 & 7,51 & & \\
\hline 5 & Sapindus rarak DC. & 7 & 2,72 & 6 & 3,94 & - & - \\
\hline 6 & Shorea sp.2 & 40 & 21,98 & 3 & 2,50 & - & - \\
\hline 7 & Symplocos fasciculata Zoll. & 6 & 3,65 & 5 & 4,49 & - & - \\
\hline 8 & $\begin{array}{l}\text { Memecylon oligoneurum Blume } \\
\text { KELOMPOK } 3\end{array}$ & 1 & 0,51 & 1 & 0,85 & - & - \\
\hline 1 & Anisoptera sp. & - & - & 10 & 5,41 & - & - \\
\hline 2 & Aquilaria sp. & - & - & 1 & 0,84 & - & - \\
\hline 3 & Archidendron sp. & - & - & 2 & 3,32 & - & - \\
\hline 4 & Calophyllum macrophyllum Scheff. & - & - & 1 & 0,77 & - & - \\
\hline 5 & Cratoxylum arborescens (Vahl) Blume & - & - & 2 & 1,74 & - & - \\
\hline
\end{tabular}




\begin{tabular}{|c|c|c|c|c|c|c|c|}
\hline \multirow[t]{2}{*}{ No } & \multirow[t]{2}{*}{ Jenis } & \multicolumn{2}{|c|}{$\begin{array}{l}\text { Hutan } \\
\text { sekunder }\end{array}$} & \multicolumn{2}{|c|}{$\begin{array}{c}\text { Hutan } \\
\text { sekunder } \\
\text { muda }\end{array}$} & \multicolumn{2}{|c|}{ Belukar tua } \\
\hline & & $\mathbf{K}$ & NK & K & NK & K & NK \\
\hline 6 & Dehaasia sp. & - & - & 1 & 0,79 & - & - \\
\hline 7 & Desmos chinensis Lour. & - & - & 6 & 4,57 & - & - \\
\hline 8 & Elaeocarpus glaber Blume & - & - & 1 & 0,70 & - & - \\
\hline 9 & Hopea sp. & - & - & 1 & 0,87 & - & - \\
\hline 10 & Maasia glauca (Hassk.) Mols, Kessler \& Rogstad & - & - & 7 & 4,65 & - & - \\
\hline 11 & Magnolia liliifera (L.) Baill. & - & - & 1 & 0,86 & - & - \\
\hline 12 & Phoebe macrophylla (Nees) Blume & - & - & 6 & 4,06 & - & - \\
\hline 13 & Pongamia sp. & - & - & 5 & 4,36 & - & - \\
\hline 14 & Shorea acuminata Dyer & - & - & 1 & 1,33 & - & - \\
\hline 15 & Shorea sp.1 & - & - & 1 & 1,38 & - & - \\
\hline 16 & Shorea teysmanniana Dyer ex Brandis & - & - & 3 & 1,83 & - & - \\
\hline & KELOMPOK 4 & & & & & & \\
\hline 1 & Gonystylus sp. & - & - & 1 & 0,73 & 1 & 1,51 \\
\hline 2 & Melicope sp. & - & - & 2 & 1,48 & 1 & 1,27 \\
\hline 3 & Pertusadina eurhyncha (Miq.) Risdale & - & - & 1 & 0,75 & 3 & 2,96 \\
\hline 4 & $\begin{array}{l}\text { Suregada glomerulata (Blume) Baill. } \\
\text { KELOMPOK } 5\end{array}$ & - & - & 6 & 3,35 & 1 & 1,77 \\
\hline 1 & Alseodaphne bancana Miq. & - & - & - & - & 7 & 9,18 \\
\hline 2 & Ardisia teysmanniana Scheff. & - & - & - & - & 5 & 6,69 \\
\hline 3 & Durio acutifolius (Mast.) Kosterm. & - & - & - & - & 5 & 5,33 \\
\hline 4 & Oncosperma horridum (Griff.) Scheff. & - & - & - & - & 1 & 1,72 \\
\hline 5 & Pometia pinnata J.R.Forst. \& G.Forst. & - & - & - & - & 1 & 1,24 \\
\hline 6 & Scorodocarpus borneensis (Baill.) Becc. & - & - & - & - & 1 & 1,27 \\
\hline 7 & Shorea palembanica Miq. & - & - & - & - & 2 & 2,53 \\
\hline 8 & $\begin{array}{l}\text { Sterculia gilva Miq. } \\
\text { KELOMPOK } 6\end{array}$ & - & - & - & - & 1 & 1,34 \\
\hline 1 & Aquilaria malaccensis Lam. & 4 & 2,21 & - & - & 1 & 2,11 \\
\hline 2 & Archidendron bubalinum (Jack) I.C.Nielsen & 4 & 3,07 & - & - & 2 & 4,79 \\
\hline 3 & Balakata baccata (Roxb.) Esser & 16 & 9,07 & - & - & 2 & 1,91 \\
\hline 4 & Canarium littorale Blume & 18 & 9,22 & - & - & 6 & 7,71 \\
\hline 5 & Dipterocarpus sp. & 5 & 2,26 & - & - & 7 & 8,69 \\
\hline 6 & Dryobalanops oblongifolia Dyer & 10 & 5,59 & - & - & 1 & 1,34 \\
\hline 7 & Intsia palembanica Miq. & 2 & 0,74 & - & - & 3 & 3,93 \\
\hline 8 & $\begin{array}{l}\text { Macaranga hypoleuca (Rchb.f. \& Zoll.) } \\
\text { Müll.Arg. }\end{array}$ & 18 & 7,94 & - & - & 35 & 36,94 \\
\hline 9 & Xylopia caudata Hook.f. \& Thomson & 28 & 11,87 & - & - & 8 & 7,58 \\
\hline
\end{tabular}


Tabel 2. Jumlah suku, jenis dan pohon per hektar di lokasi penelitian

\begin{tabular}{lccc}
\hline \multicolumn{1}{c}{ Tipe hutan } & $\begin{array}{c}\text { Jumlah } \\
\text { suku }\end{array}$ & $\begin{array}{c}\text { Jumlah } \\
\text { jenis }\end{array}$ & $\begin{array}{c}\text { Jumlah pohon } \\
\text { (N/ha) }\end{array}$ \\
\hline $\begin{array}{l}\text { Hutan sekunder } \\
\text { tua } \\
\text { Hutan sekunder }\end{array}$ & 33 & 55 & 642 \\
$\begin{array}{l}\text { muda } \\
\text { Belukar tua }\end{array}$ & 31 & 56 & 450 \\
\hline
\end{tabular}

Tabel 3. Jenis-jenis pohon dominan berdiameter $\geq$ $10 \mathrm{~cm}(\mathrm{NK}>10 \%)$ di lokasi penelitian.

\begin{tabular}{|c|c|c|c|}
\hline No. & Tipe hutan & $\begin{array}{c}\text { Kerapatan } \\
\text { (N/ha) }\end{array}$ & $\begin{array}{c}\text { Nilai } \\
\text { kepentingan (\%) }\end{array}$ \\
\hline & Sekunder tua & & \\
\hline 1 & $\begin{array}{l}\text { Calophyllum } \\
\text { macrocarpum }\end{array}$ & 74 & 27,88 \\
\hline 2 & Shorea sp. & 40 & 21,98 \\
\hline 3 & Gironniera nervosa & 50 & 19,99 \\
\hline 4 & Lithocarpus gracilis & 35 & 17,63 \\
\hline 5 & $\begin{array}{l}\text { Palaquium } \\
\text { amboinense }\end{array}$ & 39 & 16,73 \\
\hline 6 & Dysoxylum excelsum & 33 & 13,69 \\
\hline 7 & Xylopia caudata & 28 & 11,87 \\
\hline 8 & $\begin{array}{l}\text { Nephelium } \\
\text { lappaceum }\end{array}$ & 26 & 11,51 \\
\hline 9 & $\begin{array}{l}\text { Endospermum } \\
\text { diadenum } \\
\text { Sekunder muda }\end{array}$ & 16 & 10,01 \\
\hline 1 & Acacia mangium & 36 & 30,07 \\
\hline 2 & $\begin{array}{l}\text { Palaquium } \\
\text { amboinense }\end{array}$ & 42 & 25,43 \\
\hline
\end{tabular}

Tabel 3 menunjukkan bahwa hutan sekunder tua di kawasan lindung Rantau Bertuah, pada tingkat pohon didominasi oleh jenis Calophyllum macrocarpum, Shorea sp., dan Gironniera nervosa. Di hutan sekunder muda jenis dominan adalah Palaquium amboinense, Shorea macroptera, dan Gironniera nervosa, sedangkan di belukar tua, Macaranga hypoleuca, Gironniera nervosa, dan Lithocarpus gracilis.

Jenis yang potensial menggantikan tegakan yang akan datang pada tingkat pancang adalah sebagai berikut: (1) di hutan sekunder tua adalah Calophyllum macrocarpum (NK= 49,57\%), Shorea macroptera (NK= 27,13\%), dan Dysoxylum excelsum ( $N K=22,88 \%$ ); (2) di hutan sekunder muda adalah Gironniera nervosa (NK=52,38\%), Palaquium amboinense ( $\mathrm{NK}=31,35 \%)$, dan Calophyllum macrocarpum (NK= 24,73\%) dan di belukar tua adalah Gironniera nervosa (NK= $56,91 \%)$, Canarium littorale ( $\mathrm{NK}=28,43 \%)$, dan Calophyllum macrocarpum ( $\mathrm{NK}=17,68 \%$ ).

Tabel 4. Perbandingan kerapatan dan jumlah jenis pohon berdiameter $\geq 10 \mathrm{~cm}$ di hutan lindung Rantau Bertuah dengan hutan lokasi lain

\begin{tabular}{|c|c|c|c|c|c|}
\hline Lokasi & $\begin{array}{l}\text { Elevasi } \\
\text { (m dpl) }\end{array}$ & $\begin{array}{l}\text { Plot } \\
\text { (Ha) }\end{array}$ & $\begin{array}{c}\text { Kerapatan } \\
\text { (N/ha) }\end{array}$ & $\begin{array}{l}\text { Jumlah } \\
\text { jenis }\end{array}$ & Sumber \\
\hline $\begin{array}{l}\text { Rantau Bertuah } \\
\text { (hutan sekunder tua) }\end{array}$ & 60 & 1 & 642 & 51 & Penelitian sekarang \\
\hline $\begin{array}{l}\text { Register 45B, Lampung Barat } \\
\text { (Hutan terganggu) }\end{array}$ & 965 & 1 & 247 & 33 & Heriyanto et al. (2019) \\
\hline $\begin{array}{l}\text { Hutan Bukit Datuk, Dumai } \\
\text { (Hutan sekunder) }\end{array}$ & 18,2 & 1 & 354 & 22 & Samsoedin et al. (2014) \\
\hline $\begin{array}{l}\text { Desa Mekar Makmur TNGL } \\
\text { (Hutan primer) }\end{array}$ & 237,6 & 1 & 687 & 110 & Samsoedin dan Heriyanto (2010) \\
\hline $\begin{array}{l}\text { Aek Nangali, TN Batang Gadis } \\
\text { (Hutan primer) }\end{array}$ & 650 & 1 & 583 & 184 & Kartawinata et al. (2004) \\
\hline $\begin{array}{l}\text { Sekundur, TNGL } \\
\text { (Hutan dibalak) }\end{array}$ & $75-100$ & 2 & 573 & 133 & Priatna et al. (2006) \\
\hline $\begin{array}{l}\text { Ketambe, TNGL } \\
\text { (Hutan primer) }\end{array}$ & $350-450$ & 1,6 & 420 & 94 & Abdulhadi (1991) \\
\hline $\begin{array}{l}\text { Seturan, Malinau, Kaltim } \\
\text { (Hutan primer) }\end{array}$ & 100 & 1 & 759 & 221 & Sheilet et al. (010) \\
\hline $\begin{array}{l}\text { Gunung Mulu, Sarawak } \\
\text { (Hutan primer) }\end{array}$ & 50 & 1 & 615 & 223 & Proctor et al. (1983) \\
\hline
\end{tabular}


Kerapatan tegakan dan jumlah jenis pohon dalam satuan luas pencuplikan merupakan salah satu kekayaan jenis di suatu komunitas (McCune \& Grace 2002). Berikut disampaikan perbandingan petunjuk jumlah jenis dan pohon di areal lain (Tabel 4.).

Tabel 4 menunjukkan bahwa kerapatan dan jumlah jenis di kawasan lindung Rantau Bertuah, Kabupaten Siak, Provinsi Riau, tergolong rendah dibandingkan dengan petak-petak hutan primer di Taman Nasonal (TN) Gunung Leuser, TN Batang Gadis, Malinau dan Gunung Mulu.

\section{Struktur tegakan dan regenerasi}

Struktur tegakan hutan adalah sebaran individu tumbuhan dalam lapisan tajuk dan dapat diartikan sebaran pohon per satuan luas dalam berbagai kelas diameternya (Bustomi et al. 2006). Secara keseluruhan struktur tegakan pohon dalam plot penelitian tersaji pada diagram profil (Gambar 2). Struktur tegakan pohon pada tiga tipe hutan adalah sebagai berikut:

1. Hutan sekunder tua (Gambar 2a) jenis pohon menjulang (>30 m) adalah Shorea macroptera $(31,5 \mathrm{~m}$ dan $32,2 \mathrm{~m})$; jenis yang mendominasi tinggi $20-30 \mathrm{~m}$ adalah Shorea sp. $(28,8 \mathrm{~m})$, Canarium littorale $(27,1 \mathrm{~m})$, dan Shorea

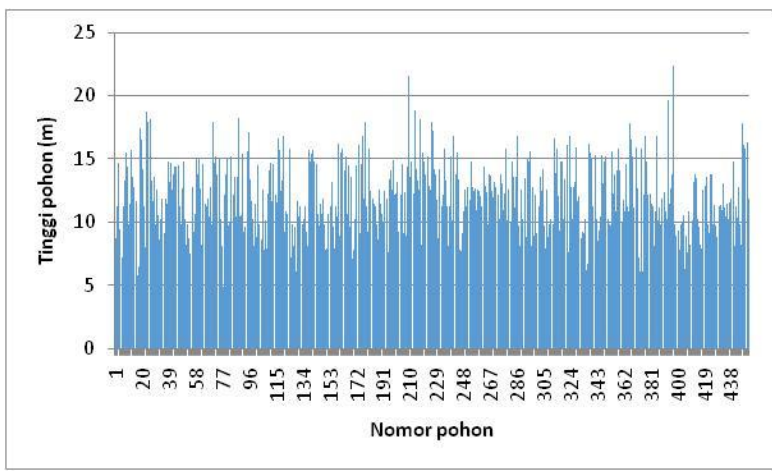

a

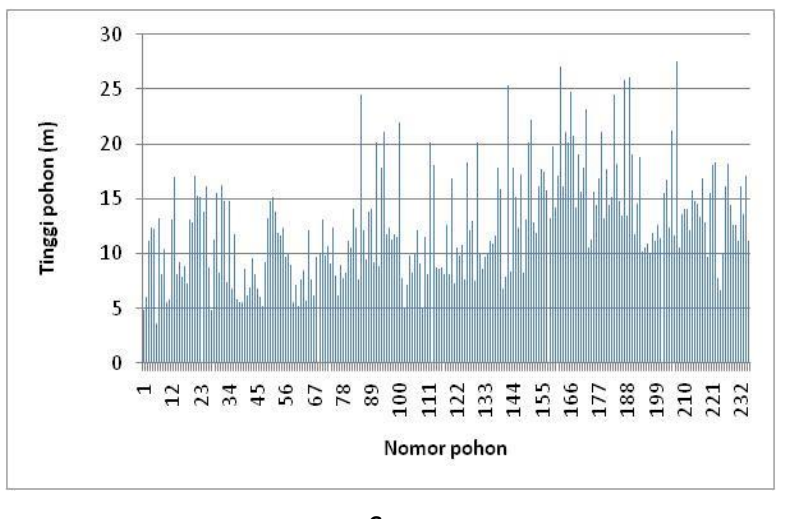

C macroptera $(26,7 \mathrm{~m})$; dan pada tinggi 5-20 m adalah Lithocarpus gracilis (19,9 m), Palaquium sumatranum (19,8 m), dan Dysoxylum excelsum (19,1 m).

2. Hutan sekunder muda (Gambar $2 b$ ) jenis-jenis pohon menjulang dengan tinggi $>20 \mathrm{~m}$ adalah Calophyllum macrocarpum (22,6 m), Parashorea smythiesii (21,6 m), dan Gironniera nervosa (19,6 $\mathrm{m})$; jenis-jenis pohon dengan tinggi 15-20 m adalah Shorea macroptera $(18,8$ m), Desmos chinensis (18,2 m), dan Palaquium sumatranum $(17,8 \mathrm{~m})$; dan jenis-jenis pohon dengan tinggi $<15 \mathrm{~m}$ adalah Dysoxylum excelsum (14,8 m), Parashorea smythiesii $(14,8$ $\mathrm{m})$, dan Gironniera nervosa (14,1 m).

3. Hutan belukar tua (Gambar 2c) jenis-jenis pohon menjulang dengan tinggi $>25 \mathrm{~m}$ adalah Magnolia bintuluensis $(27,5 \mathrm{~m})$, Shorea macroptera dan Gluta renghas $(26,1 \mathrm{~m}) ;(27,1$ $\mathrm{m})$.

Jenis yang mendominasi tinggi $>20-25 \mathrm{~m}$ adalah Macaranga hypoleuca $(24,7 \mathrm{~m})$, Shorea macroptera $(24,5 \mathrm{~m})$, dan Magnolia bintuluensis $(22,2 \mathrm{~m})$; dan mendominasi tinggi 15- $\leq 20 \mathrm{~m}$ adalah Alseodaphne bancana (19,8 m), Lithocarpus gracilis $(19,1 \mathrm{~m})$, dan Shorea leprosula $(19,1 \mathrm{~m})$.

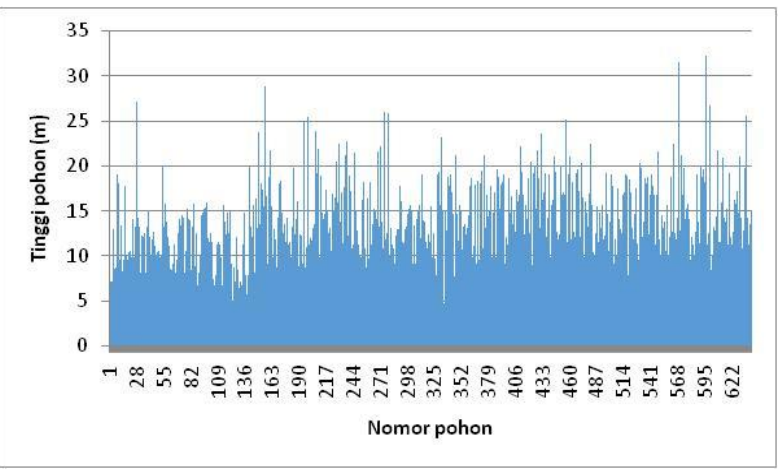

b

Gambar 2. Diagram profil tegakan hutan di lokasi penelitian:

a. Hutan sekunder tua,

b. Hutan sekunder muda,

c. Hutan belukar tua.

(Diagram profil dibuat menurut Kartawinata et al, 2004) 
Sebaran kelas diameter untuk semua pohon 10-19 cm, 20-29 cm, 30-39 cm, dan $\geq 40 \mathrm{~cm}$ ditampilkan dalam Gambar 3. Struktur tegakan hutan tidak selalu sama walaupun pada tempat yang sama, karena perbedaan kemampuan pohon dalam memanfaatkan energi matahari, unsur hara/mineral dan air, serta sifat kompetisi. Oleh karena itu dalam tegakan hutan sebaran kelas diameter pohon bervariasi (Ewusie 1980).

Dalam hutan alami yang sudah mencapai keseimbangan jumlah pohon semakin menurun dari kelas diameter kecil ke kelas diameter besar dan menaik lagi di ujung terbesar kelas diameter, sehingga bentuk kurva sebaran pohon menyerupai "J" terbalik (Sokpon \& Biaou 2002). Bentuk kurva J terbalik merupakan karakteristik struktur populasi semua umur jenis-jenis yang toleran terhadap lindungan (shade-tolerant). Dalam plot penelitian di hutan lindung Rantau Betuah, hanya sedikit sekali jenis yang menunjukkan karakteristik tersebut, termasuk Calophyllum macrocarpum, Endospermum diadenum, Palaquium amboinense,

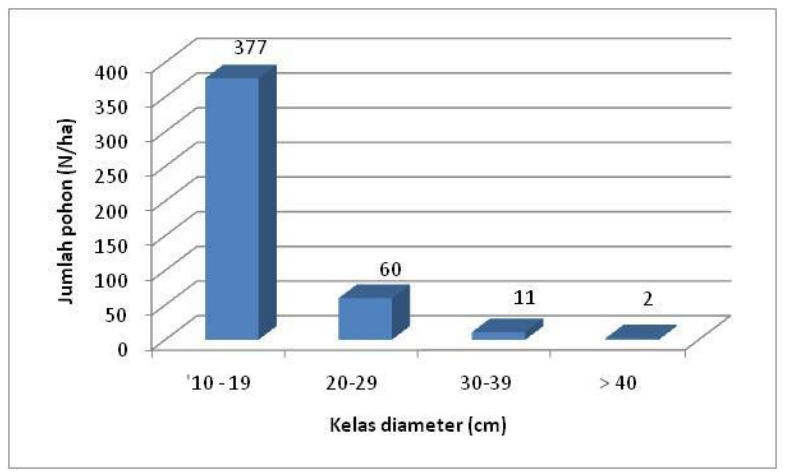

a

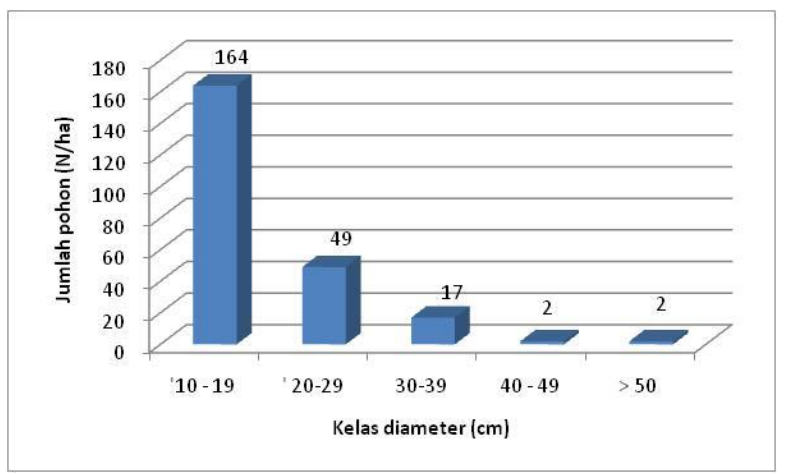

C
Shorea macroptera, dan Shorea sp. dengan diameter $10-50 \mathrm{~cm}$ di hutan sekunder tua; Calophyllum macrocarpum, Gironniera nervosa, dan Shorea macroptera di hutan sekunder muda; dan tidak ada di Hutan Belukar Tua. Gambar 3, menunjukkan kurva sebaran jumlah pohon untuk semua jenis menurut kelas diameter di hutan sekunder tua, hutan sekunder muda dan hutan belukar tua. Tampak bahwa sebaran jumlah pohon menurut kelas diameter tidak normal dengan kurva yang tidak berbebntuk J terbalik tetapi berbentuk L, yang menunjukkan populasi pohon kecil sekali pada diameter terbesar. Umumnya di hutan alami di Indonesia kurva jumlah pohon menurut kelas diameter normal, berbentuk J terbalik (Samsoedin \& Heriyanto 2010). Dalam hutan klimaks nilai kerapatan tinggi untuk jenisjenis berdiameter kecil, yang menyumbangkan kekayaan jenis dalam petak merupakan akibat gangguan pada masa lampau (Sheil et al. 2010).

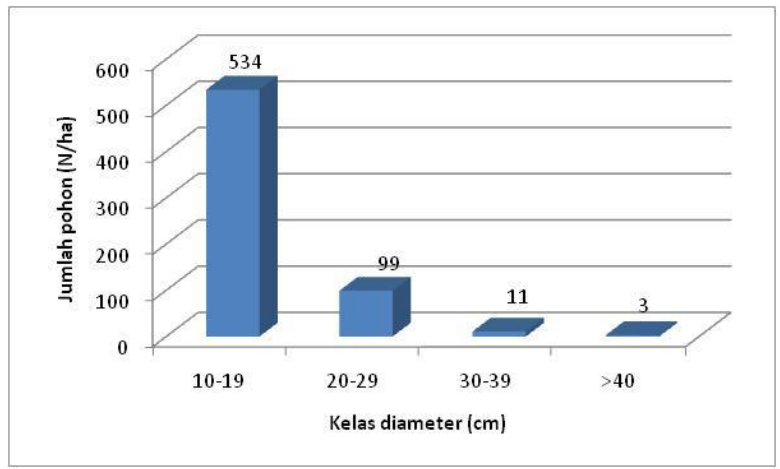

b

Gambar 3. Struktur tegakan pohon berdasarkan hubungan antara kelas diameter dan jumlah pohondi lokasi penelitian: a. Hutan sekunder tua; b. Hutan sekunder muda; dan c. Hutan belukar tua 
Regenerasi merupakan mekanisme sebuah organisme untuk mempertahankan dan melanjutkan kehadirannya, yang dalam tegakan hutan dicerminkan oleh profil lengkap jumlah individu di sepanjang gradasi kelas diameter dari semai sampai pohon dengan diameter paling besar (Sadeli et al. 2018). Proses regenerasi dalam hutan tropik merupakan proses yang kompleks karena bergantung kepada banyak faktor termasuk pembentukan rumpang alami (Richards 1996, Whitmore 1986). Regenerasi merupakan fenomena alam yang menunjukkan bahwa pohon yang muda akan menggantikan pohon dewasa yang hilang karena sesuatu sebab, misalnya ditebang, terbakar, tumbang (bencana alam) atau mati secara fisiologis. Dalam tegakan hutan sekunder tua, sekunder muda dan belukar tua, jenis-jenis yang beregenerasi baik adalah jenisjenis yang mendominasi regenerasi lengkap (tingkat pohon, pancang, dan semai) serta menyebar di setiap plot penelitian adalah Calophyllum macrocarpum, Dillenia excelsa, dan Gironniera nervosa yang tercantum dalam Tabel 5.

Suksesi merupakan salah satu cara untuk mengelola Kawasan Hutan Lindung Rantau Bertuah. Jenis-jenis yang ada dan akan mempertahankan kehadirannya dalam hutan di masa yang akan datang adalah jenis-jenis yang saat ini diwakili dalam semua kelas diameter, termasuk Calophyllum macrocarpum, Endospermum diadenum, Gironniera nervosa, Palaquium amboinense, Shorea macroptera, dan Shorea sp.

Tabel 5. Nilai kepentingan (NK) jenis pohon dengan regenerasi lengkap dalam tiga tegakan hutan di lokasi penelitian

\begin{tabular}{|c|c|c|c|c|c|}
\hline \multirow{2}{*}{ No } & \multirow{2}{*}{ Tipe hutan } & \multirow{2}{*}{ Suku } & \multicolumn{3}{|c|}{ NK (\%) } \\
\hline & & & Semai & Pancang & Pohon \\
\hline & Sekunder tua & & & & \\
\hline 1 & Calophyllum macrocarpum. & Clusiaceae & 86,31 & 49,57 & 27,88 \\
\hline 2 & Dialium indum & Leguminosae & 5,35 & 19,65 & 9,07 \\
\hline 3 & Dillenia excelsa & Dilleniaceae & 2,68 & 1,99 & 0,49 \\
\hline 4 & Dysoxylum excelsum & Meliaceae & 12,93 & 22,88 & 13,69 \\
\hline \multirow[t]{2}{*}{5} & Gironniera nervosa & Cannabaceae & 9,01 & 22,20 & 19,99 \\
\hline & Sekunder muda & & & & \\
\hline 1 & Calophyllum macrocarpum & Clusiaceae & 75,30 & 24,73 & 30,07 \\
\hline 2 & Dillenia excelsa & Dilleniaceae & 13,02 & 4,94 & 2,46 \\
\hline 3 & Diospyros ulo & Ebenaceae & 7,53 & 9,58 & 2,35 \\
\hline 4 & Dysoxylum excelsum & Meliaceae & 18,51 & 12,36 & 0,70 \\
\hline \multirow[t]{2}{*}{5} & Gironniera nervosa & Cannabaceae & 20,55 & 52,38 & 0,79 \\
\hline & Belukar tua & & & & \\
\hline 1 & Alseodaphne bancana & Lauraceae & 12,44 & 13,00 & 9,18 \\
\hline 2 & Ardisia teysmanniana & Primulaceae & 7,29 & 8,51 & 6,69 \\
\hline 3 & Calophyllum macrocarpum & Clusiaceae & 10,32 & 17,68 & 7,27 \\
\hline 4 & Dillenia excelsa & Dilleniaceae & 10,32 & 7,35 & 1,34 \\
\hline 5 & Gironniera nervosa & Cannabaceae & 47,65 & 56,91 & 22,48 \\
\hline
\end{tabular}

\section{KESIMPULAN}

Berdasarkan struktur dan komposisi jenis, hutan di plot penelitian merupakan hutan sekunder berbeda umur yang sedang berkembang. Hutan sekunder berasal dari penebangan selektif hutan alami seperti ditunjukkan oleh kehadiran pohon-pohon berdiameter besar yang tertinggal, termasuk jenis Dipterocarpaceae. Keanekaragaman jenis dalam hutan sekunder ini tidak terlalu tinggi yang hanya 73 jenis dalam areal plot seluas 3 ha yang lebih kecil dari pada kekayaan jenis di hutan primer dan hutan sekunder di tempat lain. Diperkirakan bahwa hutan primer sebelum penebangan didominasi oleh jenis-jenis Dipterocarpaceae, yang karena kegiatan manusia berubah menjadi hutan sekunder yang didominasi oleh jenis-jenis non-Dipterocarpaceae. Hutan sekunder dalam plot penelitian ini bila tidak ada gangguan dan sumber biji tersedia akan terus berkembang secara alami mengikuti proses suksesi menuju ke hutan klimaks yang serupa dengan 
aslinya. Proses restorasi atau pemulihan dengan menanam jenis-jenis pohon yang khas di hutan primer di kawasan Lindung Rantau Bertuah dan sekitarnya, terutama jenis-jenis langka, endemik dan jenis-jenis yang mempunyai nilai manfaat ganda, termasuk jenis buah-buahan dan jenis-jenis berkhasiat obat-obatan. Seiring dengan restorasi ini upaya mencegah perambahan dan pembakaran hutan ditingkatkan. Selain dari itu kawasan lindung ini dapat dijadikan situs wisata alam dan situs penelitian sehingga konservasi dan pengelolaan hutan lindung berbasis ilmiah dapat dilaksanakan.

\section{UCAPAN TERIMA KASIH}

Dalam pelaksanaan penelitian ini penulis mengucapkan banyak terima kasih kepada segenap Direksi PT. Asia Pulp and Paper dan Sinar Mas Group Indonesia.

\section{DAFTAR PUSTAKA}

Abdulhadi R. 1991. A Meliaceae forest in Ketambe, Gunung Leuser National Park, Sumatera, Indonesia with special reference to the status of dipterocarp species. Proceedings of the Fourth Round-Table Conference on Dipterocarps. Biotrop Special Publication No. 41. Bogor.

Anonim. 2017. Analisis mengenai dampak lingkungan pemanfaatan hasil hutan kayu pada hutan tanaman PT. Riau Abadi Lestari, Siak, Riau.

BPS/Badan Pusat Statistik. 2017. Siak Dalam Angka. Badan Pusat Statistik Kabupaten Siak. Provinsi Riau.

Bustomi S, Wahjono D, Heriyanto NM. 2006. Klasifikasi potensi tegakan hutan alam berdasarkan citra satelit di kelompok hutan Sungai Bomberai-Sungai Besiri di Kabupaten Fakfak, Papua. Jurnal Penelitian Hutan dan Konservasi Alam 3(4): 437-458.

Campbell NA, Reece JB, Mitchell LG. 2002. Biologi (terjemahan). Penerbit Erlangga. Jakarta.

Corlett RT. 1991. Plant succession on degraded land in Singapore. Journal of Tropical Forest Science 4(2): 151-161.

Cox GW. 1992. Laboratory Manual of General Ecology. Second Ed. W. C. Brown Company Publisher. Dubuque, lowa.
Dharmawan IWS, Samsoedin I. 2012. Dinamika potensi biomassa karbon pada landskap hutan bekas tebangan di Hutan Penelitian Malinau. Jurnal Penelitian Sosial dan Ekonomi Kehutanan 9(1): 12-20.

Ewusie JY. 1980. Pengantar Ekologi Tropika. (terjemahan). ITB-Press. Bandung.

Gillison AN. 2001. Vegetation Survey and Habitat Assessment of the Tesso Nilo Forest Complex, Pekanbaru, Riau Province, Sumatra, Indonesia. Report prepared for WWF-US. (October-November, 2001). Center for Biodiversity Management, Yungaburra, Australia

Heriyanto NM, Samsoedin I, Kartawinata K. 2019. Trre species diversity, structural characteristics and carbon stock in a onehectare plot of the protection forest area in West Lampung Regency, Indonesia. Reinwardtia 18(1): 1-18.

High Carbon Stock/HCS Approach. 2017. Pendekatan Stok Karbon Tinggi Mempraktekkan Nihil Deforestasi. The HCS Approach Toolkit, Module 4, Version 2.0. Kuala Lumpur, HCS Approch Steering Group.

Irwanto. 2007. Analisis strukutur dan komposisi vegetasi untuk pengelolaan kawasan hutan lindung Pulau Marsegu, Kabupaten Seram Barat, Provinsi Maluku. UGM. Yogyakarta. hal. 1-5.

Kartawinata K. 1994. The use of secondary forest species in rehabilation of degraded forest lands. Journal of Tropical Forest Science 7(1): 76-86.

Kartawinata K, Samsoedin I, Heriyanto NM, Afriastini JJ. 2004. A tree species inventory in a one-hectare a plot at the Batang Gadis National Park, North Sumatra, Indonesia. Reinwardtia 12(2): 145-157.

Kartawinata K. 2013. Diversitas ekosistem alami Indonesia. Penerbit Yayasan Pustaka Obor Indonesia. Jakarta.

Keßler PJA, Pelser PB, Ridsdale CF, Sidiyasa K. 2000. Secondary Forest Trees of Kalimantan, Indonesia. MOFEC-Tropenbos-Kalimantan Project. Balikpapan.

Kusmana C. 2011. Metode Survei Vegetasi. IPB Press. Bogor. 
Laumonier Y. 1997. The Vegetation and Physiography of Sumatra. Kluwer Academic Publishers. Utrecht.

Laumonier Y, Uryu Y, Stuwe M, Budiman A, Setiabudi B, Hadian O. 2010. Eco-floristic sectors and deforestation threats in Sumatra: identifying new conservation area network priorities for ecosystem-based land use planning. Biodiversity and Conservation 19: 1153-1174. DOI 10.1007/s10531-0109784-2.

McCune B, Grace JB. 2002. Analysis of Ecological Communities, MJM Software Design. Gleneden Beach. Oregon.

Mueller-Dombois D, Ellenberg H. 2016. Ekologi vegetasi: Tujuan dan Metode (terjemahan). LIPI Press dan Yayasan Pustaka Obor. Jakarta.

Nelson BW, Mesquita R, Periera JLG, De Souza SGA, Batista GT, Couto LB. 1999. Allometric regressions for improved estimate of secondary forest biomass in the central Amazon. Forest Ecology and Management 117 : 149-167.

Onrizal, Ismail, Perbatakusuma EA, Sudjito $H$, Suprijatna J, Wijayanto IH. 2008. Struktur vegetasi dan simpanan karbon hutan hujan primer di Batang Toru, Sumatera Utara. Jurnal Biologi Indonesia 5(2): 187-199.

Polosakan R. 2001. Komposisi jenis pohon di hutan kawasan Taman Nasional Bukit Tigapuluh, Provinsi Riau. Proyek inventarisasi dan karakterisasi sumberdaya hayati. Laporan Teknik. Pusat Penelitian Biologi, LIPI. Bogor.

Priatna D, Kartawinata K, Abdulhadi R. 2006. Recovery of a lowland Dipterocarp forest twenty two years after selective logging at Sekundur, Gunung Leuser National Park, North Sumatera, Indonesia. Reinwardtia 12(3): 237-251.

Proctor J, Anderson JM, Chai P, Wallack HM. 1983. Ecological studies in four constasting tropical lowland rain forests in Gunung Mulu National Park. I. Forest Environment, structure and floristics. Journal of Ecology 71: 237-260.

Pusat Penelitian Tanah dan Agroklimat. 1993. Peta Tanah Pulau Sumatera. Badan Penelitian dan Pengembangan Pertanian, Departemen Pertanian. Bogor.
Rahmah, Kartawinata K, Nisyawati, Wardhana, Nurdin E. 2016. Tree species diversity in the lowland forest of the core zone of the Bukit Duabelas National Park, Jambi, Indonesia. Reinwardtia 15(1): 11-26.

Richards PW. 1996. The Tropical Rainforest: An Ecological Study. $2^{\text {nd }}$ Edition, Cambridge University Press. Cambridge.

Riswan S, Kartawinata K. 1988. A lowland dipterocarp forest 35 years after pepper plantation in East Kalimantan. dalam Soemodihardjo S (Ed.). Some Ecological Aspects of Tropical Forest of East Kalimantan: A Collection of Research Reports. MAB Indonesia Contribution No. 48, Indonesian National MAB Committee, Indonesian Institute of Sciences, Jakarta.

Rosalina Y, Kartawinata K, Nisyawati, Nurdin E, Supriatna J. 2013. Kandungan karbon di hutan rawa gambut kawasan konservasi PT National Sago Prima, Kepulauan Meranti, Riau. Buletin Kebun Raya 16(2): 115-130.

Rosalina Y, Kartawinata K, Nisyawati, Nurdin E, Supriatna J. 2014. Floristic composition and structure of a peat swamp forest in the conservation area of the PT National Sago Prima, Selat Panjang, Riau, Indonesia. Reinwardtia 14(1): 193-210.

Sadili A, Kartawinata K, Soedjito H, Sambas E. 2018. Tree species diversity in a pristine montane forest previously untouched by human activities in Foja Mountains, Papua, Indonesia. Reinwardtia 17(2): 133-154.

Samsoedin I, Heriyanto NM, Bismark M. 2014. Keanekaragaman hayati flora dan fauna di kawasan hutan Pertamina Bukit Datuk Dumai, Propinsi Riau. Jurnal Penelitian Hutan dan Konservasi Alam 11(1): 77-89.

Samsoedin I, Heriyanto NM. 2010. Struktur dan komposisi hutan pamah bekas tebangan ilegal di kelompok hutan Sei Lepan, Sei Serdang, Taman Nasional Gunung Leuser, Sumatera Utara. Jurnal Penelitian Hutan dan Konservasi Alam 8(3): 299-314.

Schmidt FH, Ferguson JH. 1951. Rainfall Types based on Wet and Dry Period Rations for Indonesia with Western New Guinea. Verhandelingen Djawatan Meteorologi dan Geofisika. Djakarta. 
Sheil D, Kartawinata K, Samsoedin I,Priyadi H, Afriastini JJ. 2010. The lowland forest tree community in Malinau, Kalimantan (Indonesian Borneo): results from a onehectare plot. Plant Ecology and Diversity 3: 59-66.

Sokpon N, Biaou SH. 2002. The use of diameter distribution in sustained use management of remnant forests in Benin: Case of Bassela forest reserve in North Benin. Forest Ecology and Management 161: 13-25.

Soil Survey Staff. 2003. Keys to Soil Taxonomy, 9th Edition. USDA Natural Resources Conservation Service. Washington DC.

Wardani M, Heriyanto NM. 2015. Autekologi damar asam Shorea hopeifolia (F.Heim) Symington di Taman Nasional Bukit Barisan Selatan, Lampung. Buletin Plasma Nutfah 21(2): 89-98.

Wardani M, Astuti IP, Heriyanto NM. 2017. Analisis vegetasi jenis-jenis Dipterocarpaceae di kawasan hutan seksi I Way Kanan, Taman Nasional Way Kambas, Lampung. Buletin Kebun Raya 20(1): 51-64.

Whitmore TC. 1986. Tropical Rain Forests of the Far East. Oxford University Press. Oxford.

The Plant List. 2013. The plant list version 1.1 (September 2013), Royal Botanic Gardens, Kew, UK. and Missouri Botanical Garden, Missouri, USA.

Whitmore TC, Tantra IGM. 1986. Tree Flora of Indonesia: Checklist for Sumatra. Forest Resarch and Development Centre. Bogor.

Whitten AJ, Damanik SJ, Anwar J, Hisyam N. 1984. The Ecology of Sumatra. Gadjah Mada University Press. Yogyakarta. 